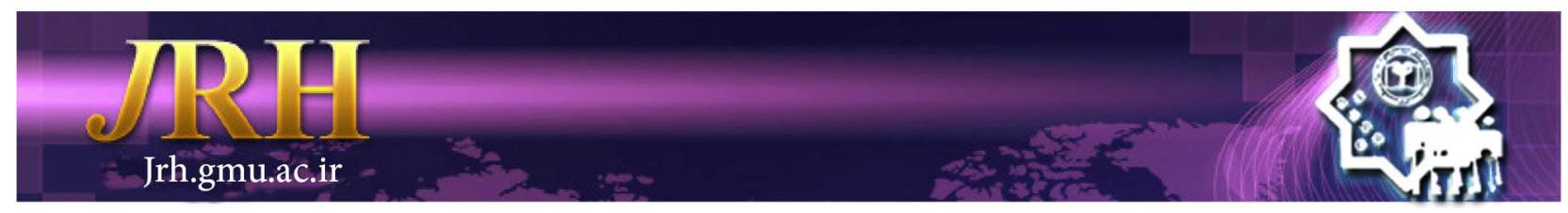

\title{
Effect of health capital on the economic growth process of Iranian provinces using generalized method of moments approach \\ Mojtaba Ghiasi ${ }^{1}$, Ahmad Sarlak ${ }^{1}$, Hadi Ghafari ${ }^{2}$
}

\author{
Journal of Research \& Health \\ Social Development \& Health Promotion \\ Research Center \\ Vol. 9, No.1, Jan \& Feb 2019 \\ Pages: $21-28$ \\ DOI: $10.29252 / j r h .9 .1 .21$ \\ Original Article
}

1. Department of Economic, School of Management, Arak Branch, Islamic Azad University, Arak, Iran

2. Department of Economic, School of Economics, Payame Noor University, Arak, Iran

Correspondence to: Ahmad Sarlak, Department of Economic, School of Management, Arak Branch, Islamic Azad University, Arak, Iran

Email: a-sarlak@iau-arak.ac.ir

Received: 26 Jan 2018

Accepted: 23 May 2018

How to cite this article: Ghiasi M, Sarlak A, Ghafari H. Effect of health capital on the economic growth process of Iranian provinces using generalized method of moments approach. $J$ Research \& Health2019; 9(1): 21- 28.

\begin{abstract}
Many studies have been conducted on the relationship between education as an indicator of human capital and economic growth in our country. However, there have been a few studies regarding the simultaneous impact of health capital and education indicators on the economic growth of the provinces up to now. In this regard, the present study examined the impact of human health indicators and educational expenditures on the economic growth of the provinces of Iran. In this study, the dynamic effect of health capital indicators and educational expenditure along with the performance of the capital assets ownership on the growth of the economies was examined using the panel data obtained from the provinces during the years $2005-2015$ by employing the generalized method of moments. The study results indicate that the fertility rate with a coefficient of 0.39 , life expectancy with a coefficient of 0.202 , and growth of household health expenditures with a coefficient of 0.045 had a positive effect on the economic growth of the provinces. However, the mortality rate with a coefficient of 0.203 had a significant negative effect on the provinces economic growth during the years under study. It was also found that educational expenditures growth and performance of capital assets ownership had a significant positive effect on the economic growth of the provinces. The health capital and its indicators are a long-term investment that should be considered as an important priority by the policymakers of the country and provinces.
\end{abstract}

Keywords: Economic Growth, Fertility Rates, Health Expenditures, Life Expectancy

\section{Introduction}

One of the main concerns of economists and policymakers in every society is economic growth. In order to target and plan for improving economic growth, it is inevitable to precisely determine the factors affecting it. Labor, physical capital, and human capital are among the most important factors that have been considered in many studies. However, in recent decades, some studies have evidenced the effects of health capital as the functions of economic growth by introducing the concept of health capital.
Knowles and Owen were among the first to regard health as one of the components of human capital in the economic growth model [1].

Health has been introduced into the growth models in recent decades. In the early 1990s, many studies were conducted to investigate the determinants of economic growth, with a small number of variables being accepted. Education and health of people in the society were among these variables. However, Mankiw, Romer, 
and Weil considered these two variables in a more general sense of human capital [2]. Then, Fogel, Barro and Sala Martin, and Barro separately examined health in growth models and the relationship between wealth and health was paid attention to $[3,4,5]$. The studies used men's life expectancy, women's life expectancy, men's elementary education, men's secondary education, women's elementary education, women's secondary education, mortality rate, health expenditures, private health expenditures, public health expenditures, and chronic disease prevalence to measure health capital.

The capital of individual health contributes to the economic growth as part of human capital. By emphasizing this concept, the factor of health capital can be introduced into the functions of economic growth. High life expectancy and low mortality rates, high fertility rates, healthy diet, medical developments, and the amount of government and household expenditures in the health sector, low-cost services, and preproduction care are some of the health features of a society.

In particular, health capital affects economic growth through four channels including higher productivity, higher skills, more savings available for investing in physical and intellectual capital, and higher labor supply.

Health and hygiene play a key role in the productivity and sustainability of the labor (World Bank) thereby affecting different mechanisms and channels of a country's growth and production. Healthier people provide a more suitable combination for production to increase productivity and economic growth [6]. One of the most important channels emphasized by most studies is the better efficiency of healthy labor compared to non-healthy labor that is considered as the direct effect of human capital on the economic growth. Moreover, improving health through increasing motivation and ability to continue studying and achieving more skills will indirectly affect the economic growth. Enhancing health conditions, on the one hand, increases the attractiveness of investment in education and educational opportunities, and on the other hand, makes people more prone to continue studying and acquiring more skills by increasing their ability to learn. In other words, improving health indicators in the society by reducing mortality and increasing the life expectancy will increase the amount of savings in the society, followed by increased physical capital, which in turn indirectly affect labor and economic growth [7]. Of course, there are some other channels for the effect of health capital on the growth. For example, evidence indicates that when the level of a society's health and hygiene improves, fewer resources will be needed for the cost of treatment in future than when this level of health not exists. Thus, this situation results in using fewer resources and fewer expenditures and greater economic growth by employing the resources in other sectors of the economy [8].

The effect of health on the labor supply is theoretically vague; however, good personal health can reduce the number of days an individual spends with illness and increase the number of healthy days available for work or leisure. On the one hand, if wages are related to productivity, health improvement is expected to increase wages when regarding healthy workers, and thus it is an incentive to increase labor supply (substitution effect). On the other hand, healthy workers may generate higher earnings over their life that consequently decreases labor supply (income effect) [9].

One of the factors affecting the labor supply is the change in fertility rate. Population aging, in general, and fertility decline, in particular, creates concerns for the economy in developing societies, including Iran. The problem of population aging, fertility decline, and its adverse effects in different countries have been accompanied by economic, political, and security issues in these countries and has led to changes in their demographic strategy in line with population growth. The young population will increase by increasing the fertility rate. Then, the population growth will have a positive effect on the young labor and effective demand of the society with a lag period. Therefore, an increase in the young population of the country to enhance the economic growth has been 
one of the main goals of the overall policies of countries, including Iran, in recent years.

With regard to the above-mentioned cases, the main objective of this study was to determine the effects of the variables of the performance of capital assets ownership, health and educational expenditures of households, life expectancy, fertility rate, and mortality rate on the economic growth of Iran provinces during 2005-2015.

\section{Method}

This is an applied descriptive survey. The model used in the study is based on the general pattern of economic growth of the panel data that has been presented by Jude Eggoh et al. It is expressed as equation 1 [10]:

Growth $_{i t}=\beta_{1}+\beta_{2} G D P_{i, t-1}+\beta^{\prime} X_{i t}+\varepsilon_{i t}$

In this model, Growth shows the real gross domestic product (GDP) rate and GDP (-1) indicates the real GDP of the previous period. X represents the vector of variables affecting the economic growth.

Since the focus of this study is on health capital, according to the theoretical framework of the relationship between health indicators and economic growth of Bargawa et al.'s model, it is necessary to enter the variables including the rates of mortality, fertility, life expectancy, and capital stock into the model [11].

Capital stock is a combination of physical capital and human capital. Finaly concluded that the simultaneous usage of educational expenditures and health expenditures could be a suitable indicator for human capital quality; therefore, these two variables are used together in the model [12].

Accordingly, Model 1 can be rewritten as follows: Growth $_{i t}=\beta_{1}+\beta_{2} L G D P_{i, t-1}+\beta_{3} \log K_{i t}+\beta_{4} \operatorname{LogHCE} E_{i t}+$ $\beta_{5} \log E D U_{i t}+\beta_{6} \log F R_{i t}+\beta_{7} \log L E_{i t}+\beta_{8} \log M R_{i t}+\varepsilon_{i t}$ In this equation, $\mathrm{i}$ and $\mathrm{t}$ represent the province and the time period.

The model variables include:

Growth: the gross domestic product of the ith province in $t$ year.

LGDP (-1): logarithm of the gross domestic product of the previous period.

LogK: logarithm of physical capital (due to the lack of information about the physical capital of the provinces). The performance of capital assets is used based on other provincial studies conducted, including Sarlak [13].

LogHCE: logarithm of household health expenditures.

LogEDU: Logarithm of household educational expenditures.

LogFR: Logarithm of fertility rate (obtained from the ratio of the number of live births in a year to the female population between 15 and 49 years in the same year).

LogLE: logarithm of the life expectancy index. LogMR: logarithm of mortality rate (obtained by dividing the number of deaths in a year to the population of the same year).

$\varepsilon$ : Error term

The presence of disturbance in a dependent variable on the right side of the panel's model studied leads to the failure of the assumption of the zero autocorrelation between independent variables and disturbance terms as one of the classical assumptions. As a result, the use of ordinary least squares methods (in the model of the panel of fixed effects and random effects) will present biased incompatible results [14]. Therefore, since there is a disturbed variable in the model in this study, the study model is dynamic and the generalized method of moments (GMM) is used for estimating. The use of the generalized method of moments eliminates this failure, namely the endogeneity of the explanatory variables of the model through instrumental variables. In order to eliminate the bias caused by the endogenous explanatory variables, it also allows all regression variables even the disturbed regression variables to be included in the model as an instrumental variable, if they do not correlate with the disturbed term [15].

Moreover, the use of the generalized method of moments with dynamic panel data provides advantages such as the inclusion of individual heterogeneity, elimination of biases in crosssectional regression, and more efficient and fewer linear estimators [16]. Furthermore, the generalized method of moments is a robust model in which both the main variables and disturbed variables can be entered into in order 
to better estimate. In order to solve the correlation problem of the disturbed dependent variable with an error term, the explanatory variables are used as instruments [17]. Therefore, according to Arlano and Band, the GMM estimation method is a suitable instrument that does not correlate with error terms. In addition, Eviews 9 software was used to estimate the study model.

All data of 30 provinces of Iran during 20052015 for the provincial gross domestic product variables and Performance of capital assets of the provinces were extracted from national and provincial yearbooks. Data of population, mortality, and fertility rates of the provinces were extracted from the yearbooks of national organization for civil registration and educational expenditures and health expenditures of the households from the statistical tables of household budgets in the urban areas of the Central Bank. GDP variables, Performance of capital assets, health, and educational expenditures are all declared according to the market prices that need to be converted into fixed prices. Therefore, 2004 has been regarded as the base year for all price indices. Health and hygienic expenditures of the provinces' households has been converted to the fixed price in 2004 with the help of the price index of health and care department of the Central Bank in different provinces. Moreover, the performance of capital assets and gross domestic products of the provinces have been converted to the fixed price in 2004 with the help of the total index of prices for goods and services for households. It should be noted that since information about the province of Alborz has not independently existed since the beginning of the study interval, the information in the province was gathered for the years that have been distinguished in the statistical yearbooks of Tehran province.

\section{Results}

The usual methods of econometric studies in the empirical work are based on the assumptions of the stationary variables studied because there is a possibility of a false estimation with nonstationary variables and relying on the results of such estimations will lead to misleading results [14]. Although the GMM method requires a few assumptions about the study data, it is necessary to examine the stationary data before estimating the model. Hence, the root test unit of Levin Lin Cho (LLU), Fisher- ADF, and Fisher- PP was used in the study.

Table 1 Results of root test of units at the levels and data difference

\begin{tabular}{|c|c|c|c|c|c|c|}
\hline \multirow[t]{2}{*}{ Variable } & \multirow[t]{2}{*}{ Test } & \multicolumn{2}{|c|}{ Test at variables level } & \multicolumn{2}{|c|}{$\begin{array}{l}\text { Test in the first-order } \\
\text { difference of variables }\end{array}$} & \multirow[t]{2}{*}{ Test Result } \\
\hline & & Coefficient & Prob. & Coefficient & Prob. & \\
\hline \multirow{3}{*}{ LogGDP } & LLC & -5.9451 & $0.0000^{*}$ & -13.8312 & $0.0000^{*}$ & \multirow{3}{*}{$\begin{array}{c}\text { Stationary at } \\
\text { Level } \\
\mathrm{I}_{(0)} \& \mathrm{I}_{(1)}\end{array}$} \\
\hline & Fisher-ADF & 85.1085 & $0.0182^{* *}$ & 159.393 & $0.0000^{*}$ & \\
\hline & Fisher-pp & 169.665 & $0.0000^{*}$ & 213.781 & $0.0000^{*}$ & \\
\hline \multirow{3}{*}{$\log K$} & LLC & $28787.4-$ & $0.0000^{*}$ & -15.5825 & $0.0000^{*}$ & \multirow{3}{*}{$\begin{array}{c}\text { Stationary at } \\
\text { Level } \\
\mathrm{I}_{(0)} \& \mathrm{I}_{(1)}\end{array}$} \\
\hline & Fisher-ADF & 37.3357 & 0.9905 & 173.431 & $0.0000^{*}$ & \\
\hline & Fisher-pp & 40.8201 & 0.9726 & 337.996 & $0.0000^{*}$ & \\
\hline \multirow{3}{*}{ LogEDU } & LLC & $20225.6-$ & $0.0000^{*}$ & -11.3222 & $0.0000^{*}$ & \multirow{3}{*}{$\begin{array}{c}\text { Stationary at } \\
\text { Level } \\
\mathrm{I}_{(0)} \& \mathrm{I}_{(1)}\end{array}$} \\
\hline & Fisher-ADF & 69.8671 & 0.1799 & 164.476 & $0.0000^{*}$ & \\
\hline & Fisher-pp & 96.3527 & $0.0020^{*}$ & 396.300 & $0.0000^{*}$ & \\
\hline \multirow{3}{*}{ LogHCE } & LLC & 79376.6- & $0.0000^{*}$ & -9.11917 & $0.0000^{*}$ & \multirow{3}{*}{$\begin{array}{c}\text { Stationary at } \\
\text { Level } \\
\mathrm{I}_{(0)} \& \mathrm{I}_{(1)}\end{array}$} \\
\hline & Fisher-ADF & 102.176 & $0.0006^{*}$ & 130.869 & $0.0000^{*}$ & \\
\hline & Fisher-pp & 189.224 & $0.0000^{*}$ & 317.795 & $0.0000^{*}$ & \\
\hline \multirow{3}{*}{ LogMR } & LLC & $25942.5-$ & $0.0000^{*}$ & -8.69614 & $0.0000^{*}$ & \multirow{3}{*}{$\begin{array}{c}\text { Stationary at } \\
\text { Level } \\
\mathrm{I}_{(0)} \& \mathrm{I}_{(1)}\end{array}$} \\
\hline & Fisher-ADF & 102.846 & $0.0005^{*}$ & 140.251 & $0.0000^{*}$ & \\
\hline & Fisher-pp & 142.668 & $0.0000^{*}$ & 298.290 & $0.0000^{*}$ & \\
\hline \multirow{3}{*}{ LogLE } & LLC & 0.28599 & 0.6156 & $4.15205-$ & $0.0000^{*}$ & \multirow{3}{*}{$\begin{array}{c}\text { Stationary at } \\
\text { Level } \\
\mathrm{I}_{(1)}\end{array}$} \\
\hline & Fisher-ADF & 10.0183 & 1.0000 & 82.2303 & $0.0300^{* *}$ & \\
\hline & Fisher-pp & 33.8945 & 0.9974 & 130.630 & $0.0000^{*}$ & \\
\hline \multirow{3}{*}{ LogFR } & LLC & -1.0209 & 0.1536 & $8.71008-$ & $0.0000^{*}$ & \multirow{3}{*}{$\begin{array}{c}\text { Stationary at } \\
\text { Level } \\
I_{(1)} \\
\end{array}$} \\
\hline & Fisher-ADF & 25.3024 & 1.0000 & 117.556 & $0.0000^{*}$ & \\
\hline & Fisher-pp & 53.8475 & 0.6987 & 245.836 & $0.0000^{*}$ & \\
\hline
\end{tabular}

For bounds tests: *,** signify rejects the null of no level relationship at the $1 \%, 5 \%$ significance levels 
According to Table 1, the variables of the logarithm of gross domestic product (LGDP), logarithm of capital assets acquisition (LK), logarithm of household educational expenditure (LEDU), logarithm of household health expenditure (LHCE), logarithm of mortality rate (LMR), logarithm of life expectancy (LLE), and logarithm of fertility rate (LFR) are stationary based on the three tests or in the first-order differential.

It should be noted that due to some Stationary variables at the level I (1), longterm equilibrium relations should be tested. For this purpose, the Cao test was used. The alternative hypothesis of this test is the cointegration. Therefore, Kao Residual Test was performed before the model estimation. Table 2 reports the results.

Table 2 The results of kao residual cointegration test

\begin{tabular}{lcc}
\hline Test & t-Statistic & Prob. \\
\hline ADF & $211338-2 /$ & 0.0135 \\
\hline
\end{tabular}

With regard to the statistics calculated in the above-mentioned test and probability of each test, the results indicate that there is a strong long-term relationship and cointegration between the variables studied in the model. In order to estimate the models through GMM, it is necessary to use instrumental variables. These variables should be chosen based on their abilities in estimating and identifying the conditions. If adding a new instrumental variable has a positive effect on the quality of estimation, the variable will be used as the instrumental variable.

The following table shows the instrumental variables used in estimating the study model.

\begin{tabular}{ll}
\multicolumn{2}{l}{ Table 3 Instrumental variables used in model estimation } \\
\hline Variable & Variable defining \\
\hline LGDP(-2,-7) & $\begin{array}{l}\text { Delay logarithms of the GDP of the provinces from two previous periods to } \\
\text { seven preceding periods } \\
\text { LK }\end{array}$ \\
The logarithm of physical capital
\end{tabular}

The following table reports the results of yearly data of the country's provinces during estimating the study model through GMM and 2005-2015.

\begin{tabular}{|c|c|c|c|c|}
\hline \multicolumn{5}{|c|}{$\begin{array}{l}\text { Dependent Variable: LGDP } \\
\text { Method: Panel Generalized Method of Moments } \\
\text { Sample (adjusted): } 2005 \text { to } 2015 \\
\text { Cross-sections included: } 30 \\
\text { Total panel (balanced) observations: } 270 \\
\text { Instrument rank: } 30\end{array}$} \\
\hline Variable & Coefficient & Std. Error & t-Statistic & Prob. \\
\hline LGDP $_{(-1)}$ & $0.360817^{*}$ & 0.011405 & 31.63671 & 0.0000 \\
\hline $\operatorname{LogK}$ & $0.027430^{*}$ & 0.003965 & 6.917452 & 0.0000 \\
\hline LogHCE & $0.044627^{*}$ & 0.008125 & 5.492518 & 0.0000 \\
\hline LogEED & $0.088446^{*}$ & 0.019531 & 4.528401 & 0.0000 \\
\hline LogFR & $0.393154^{*}$ & 0.099689 & 3.9433496 & 0.0001 \\
\hline LogLE & $0.201746^{* *}$ & 0.114214 & 1.766384 & 0.0875 \\
\hline LogMR & $-0.203976^{*}$ & 0.031953 & -6.383695 & 0.0000 \\
\hline J-statistic & 29.37830 & - & - & 0.168093 \\
\hline
\end{tabular}

Compatibility of GMM estimation depends on the validity of the zero cyclic autocorrelation of error terms and instruments that can be performed by J-statistic presented by Hansen [18]. Hansen's J-test was provided for over identifying restrictions so that it 
could measure how close the GMM is to zero [19]. Therefore, this test is used to assess the validity of the instruments and verify the condition of over identification restrictions. If the probability value of the test is higher, the instrumental variables used in the respective pattern will have greater validity. With regard to the information estimated in Table 3 , the probability value of the J-test is estimated to be 0.168 . Thus, H0 (i.e., the validity of the instruments defined in the model) could not be rejected.

The results of the model estimation suggest that all the variables coefficients are significant and have an expected sign consistent with both theoretical and experimental studies.

Real gross domestic product (GDP) of the previous period, health expenditures, educational expenditures, credits on the performance of capital assets, fertility rate, and life expectancy had a positive effect on the economic growth and mortality rate had a negative effect on the economic growth in Iran provinces during the study interval.

\section{Discussion}

This study investigated the effect of health capital on the economic growth in provinces of Iran using the generalized method of moments (GMM) during 2005-2015. According to the results, the GDP coefficient of the previous period is positive and significant, indicating that the economic growth of the provinces increases by $36 \%$ with a one-percent increase in the variable. This result is completely compatible with the studies conducted by Jude et al. [10] and Heidari et al. [8]. Another result of the estimation was the positive and significant coefficient in the growth of the performance of capital assets. A one-percent increase in the assets can only increase the provinces' economic growth by 0.027 , which is similar to the results reported by Sarlak [13], Aghaei [20], and Rahmani [21].

Moreover, every one percent increase in the health and education expenditures of households and fertility rate and life expectancy will increase the economic growth of the provinces by $0.045,0.088,0.39$, and $0.2 \%$, respectively. On the other hand, a one-percent reduction in mortality rate will increase the economic growth of the provinces by $0.2 \%$. These results are compatible with many of the results of previous studies, including Bargava et al. [11], Quarry [22], Rabiei [23], Fattahi et al. [24], and Lotfipour [25].

This study had two limitations that should be regarded when interpreting the results. First, In addition to the variables introduced into the model, other variables, including separation of public and private health expenditures, the prevalence of diseases, and the level of health could be effective in the health of the capital and economic growth; therefore, due to the lack of data, they were not analyzed in the study. Second, the data for 2016 and 2017 were not available for all provinces, and it was not possible to increase the number of the years studied.

\section{Conclusion}

Comparison of the coefficients of variables in the estimation model demonstrated that the effect of health capital, including fertility rate, life expectancy, and mortality rate, is greatly outweighed by the effects of the performance of capital assets (physical capital) and educational expenditures on the provinces economic growth.

Other results of this research are the larger and more significant contribution of the effects of health capital and less significant contribution of physical investment to the economic growth of the country's provinces. Thus, the view that the problem of the lack of physical capital is considered as the main challenge of the provinces in the growth process is rejected, and a new perspective that introduces health capital as a cornerstone of the growth process is accepted. Hence, the practitioners can provide more economic growth for provinces and the whole country by allocating resources to health capital.

With regard to the high fertility rate coefficient compared to the other variables studied, it was found that fertility rate had a 
great effect on the economic growth of Iran's provinces. The development of social services, media culturalization about the better education of children, investment on intellectual development and better work for adolescents to educate a young labor with high intellectual potential are among the most important policies proposed by this study in order to direct the government's policy for encouraging marriage and childbearing to progress industrial and economic domains of the country compared to other societies. The positive coefficient of life expectancy in the estimation model suggests that increasing life expectancy is one of the most important variables that can affect accelerating economic growth in the provinces. Health and hygienic awareness, promotion of healthy living, exercise and physical activities, promotion of healthy nutrition, and improvement of the environment are other most important actions that can increase life expectancy. Another important variable in the estimation model is the mortality rate, which has a negative effect on the economic growth of the provinces. Therefore, it is very important to reduce the rate of mortality in order to achieve higher economic growth in the provinces. Reducing factors affecting early mortality such as accidents and illnesses, health improvement, prevention of chronic diseases, expansion of hospital services, and health insurance are among the most important actions that should be prioritized by provincial policymakers.

\section{Contribution}

Study design: MG, AS

Data collection and analysis: $\mathrm{MG}, \mathrm{AS}, \mathrm{HG}$

Manuscript preparation: $\mathrm{MG}, \mathrm{AS}$

\section{Conflict of Interest}

"The authors declare that they have no competing interests."

\section{Acknowledgments}

This paper is derived from a Ph.D. dissertation entitled "study of the effect of health capital and social capital on the economic growth of the provinces of Iran" that was conducted without any financial and organizational support.

\section{Funding}

The author (s) received no financial support forthe research, authorship and/or publication of this article.

\section{Reference}

1- Knowles S, Owen D. Health capital and cross-country variation in income per capita in the Mankiw-RomerWeil model. Econ Lett1995; 48(1): 99-106.

2- Mankiw NG, Romer D, Weil DN. A Contribution to the empirics of economic growth. $Q J$ Econ 1992; 107 : 407-37.

3- Fogel RW. Economic growth, population theory, and physiology: the bearing of long-term processes on the making of economic policy. Am Econ Rev1994; 84(3): 369-95.

4- Barro RJ, Sala-i-Martin X. Economic growth. NewYork: McGraw-Hill; 1995.

5- Barro RJ. Health and economic growth. Annals of Economics and Finance 2013; 14(2): 329-66.

6- Salmani B, Mohammadi AR. Investigating effect of government health expenditures on Iran's economic growth. Iranian Journal of Economic Research2009; 13(39): 73-93.

7- Ganbari A, Baskha M. Investigating the effects of public health care expenditure on Iranian economic growth (1959-2004). Journal of Economic Research (Tahghighat-E-Eghtesadi)2008; 43(2): 187-224.

8- Heidari H, Faalju H, Nazarian E, Mohammadzadeh Y. Social capital, health capital and economic growth in the middle east countries. Journal of Economic Growth and Development Research2013; 3(11): 5774.

9- Strauss J, Thomas D. Health, nutrition and economic development. J Econ Lit1998; 36(2): 766-817.

10- Jude E, Hilaire H, Ana G. Education health and economic growth in African countries. J Econ Dev2015; 40(1): 93-111.

11- Bhargava A, Jamison DT, Lau LJ, Murray CJ. Modeling the effects of health on economic growth. $J$ Health Econ2001; 20(3): 423-40..

12- Finlay J. The role of health in economic development. Program on the Global Demography of Aging. PGDA Working Paper2007; 21.

13- Sarlak A, Hozhabr Kiani K. The effects of and health expenditure on economical growth in Iran s' provinces. Applied Economics Studies of Iran2015; 4(13): 171-85. 14- Baltagi BH. Econometric analysis of panel data. 5th Edition. Chichester: John Wiely \& Sons Ltd; 2013.

15- Greene WH. Econometric Analysis. 7th Ed. London, England: Pearson; 2011. 
16- Nadiri M, Mohammadi T. Estimating an institutional structure in economic growth using GMM dynamic panel data method. Journal of Economical Modeling2011; 5(3): 1-24.

17- Arellano M, Bond S. some tests of specification for panel data: Monte Carlo evidence and an application to employment equations. Rev Econ Stud1991; 58(2): 277-97. 18- Hansen LP, Singleton KJ. Generatized instrumental variable estimation of nonlinear rational expwctations models. Econometrica 1982; 50(5): 1269-86.

19- Shahiki Tash MN, Mohamadzadeh A, Roshan R. Estimating, evaluation and comparison consumptionbased asset pricing models with GMM method and HJ function. Journal of Economic Research (Tahghighat-EEghtesadi)2017; 52(2): 369-94.

20- Aghaei M, Rezagholizadeh M, Bagheri F. The effect of human capital on economic growth: the case of Iran's provinces. Journal of Research and Planning in Higher
Education2013; 19(1): 21-44.

21- Rahmani T, Abbasi Nezhad H, Amiri M. The impact of social capital on Iran's economic growth. The Economic Research2007; 7(2): 1-30.

22- Cooray A. does health capital have differential effects on economic growth? Appl Econ Lett2013; 20(3): 244-49.

23- Rabiei M, Heidari S, Shariat Bahadori M, Kani S. Effect of health indicators on economic growth: case study of developed and developed countries. Economic Journal2013; 13(7\&8): 73-88.

24- Fattahi S, Soheili K, Rashadat S, Karimi P. The relationship between human capital of health and economic growth in OPEC countries. Journal of Health Management 2011; 3(3\&4): 37-51.

25- Lotfalipour M, Falahi M, Borji M. The effects of health indices on economic growth in Iran. Journal of Health Administration2012; 14(46): 57-70.

\footnotetext{
Copyright(C) 2016 ASP Ins. This open-access article is published under the terms of the Creative Commons Attribution-NonCommercial 4.0 International License which permits Share (copy and redistribute the material in any medium or format) and Adapt (remix, transform, and build upon the material) under the Attribution-NonCommercial terms.
} 